\title{
Cataract surgery in the setting of severe pathologic myopia with high axial length: use of pars plana lensectomy and vitrectomy
}

This article was published in the following Dove Press journal:

Clinical Ophthalmology

27 May 2016

Number of times this article has been viewed

\author{
Daniel Gologorsky \\ Harry W Flynn Jr \\ Department of Ophthalmology, \\ Bascom Palmer Eye Institute, \\ University of Miami Miller School \\ of Medicine, Miami, FL, USA
}

Correspondence: Harry W Flynn Jr Department of Ophthalmology, Bascom Palmer Eye Institute, University of Miami Miller School of Medicine, 900 NW 17th Street, Miami, FL 33I26, USA

Tel +l 30532661 I8

Fax + I 3053266417

Email hflynn@med.miami.edu

\begin{abstract}
Cataract surgery in patients with pathologic myopia and high axial length can be challenging for a variety of reasons, including imprecise intraocular lens calculations in eyes with posterior staphylomas and intraoperative complications such as suprachoroidal hemorrhage, posterior capsular rupture, and retinal tears. Although most surgeons recommend standard phacoemulsification and preservation of the posterior capsule in these cases, an alternative approach presented in this series entails the removal of the lens through the pars plana and removal of formed vitreous during the concurrent procedure.
\end{abstract}

Keywords: cataract surgery, pathologic myopia, high axial length, aphakia

\section{Introduction}

Cataract surgery in patients with pathologic myopia can be challenging for a variety of reasons. ${ }^{1}$ Preoperatively, intraocular lens (IOL) calculations may be imprecise given the limitations in biometric technology assessing longer axial length in eyes with posterior staphylomas and poor fixation due to macular disease. ${ }^{2}$ Intraoperatively, complications including suprachoroidal hemorrhage, posterior capsular rupture, dropped lens material, and retinal tears may manifest. ${ }^{1,3,4}$ Nonetheless, most surgeons recommend standard phacoemulsification, preservation of the posterior capsule, and placement of IOL in these patients..$^{5}$ An alternative approach for cataract surgery in the context of pathologic myopia is the removal of the lens through the pars plana and removal of formed vitreous during the concurrent procedure. The present case series illustrates this surgical technique in two patients with pathologic myopia whose axial lengths were $\geq 32 \mathrm{~mm}$.

\section{Case report I}

A 51-year-old woman developed progressive cataracts in both eyes. Her best-corrected visual acuity (BCVA) was 20/50 in her right eye (RE) and 20/60 in her left eye (LE). Intraocular pressures were $17 \mathrm{mmHg}$ in both eyes. The patient's manifest refraction was RE $-23.75+1.00 \times 99$ and LE $-21.50+0.75 \times 075$. A-scan measurements demonstrated an axial length of RE $32 \mathrm{~mm}$ and LE $28 \mathrm{~mm}$. On clinical examination, there were significant nuclear sclerotic and cortical cataracts in both eyes. Her posterior segment was notable for bilateral posterior vitreous detachments, tilted discs, peripapillary atrophy, macular retinal pigment epithelial changes, and large staphylomas in the posterior poles of both eyes (Figure 1). The patient underwent a pars plana vitrectomy and lensectomy (PPV/PPL) sequentially in both eyes over 2 months. At her 1-year postoperative 

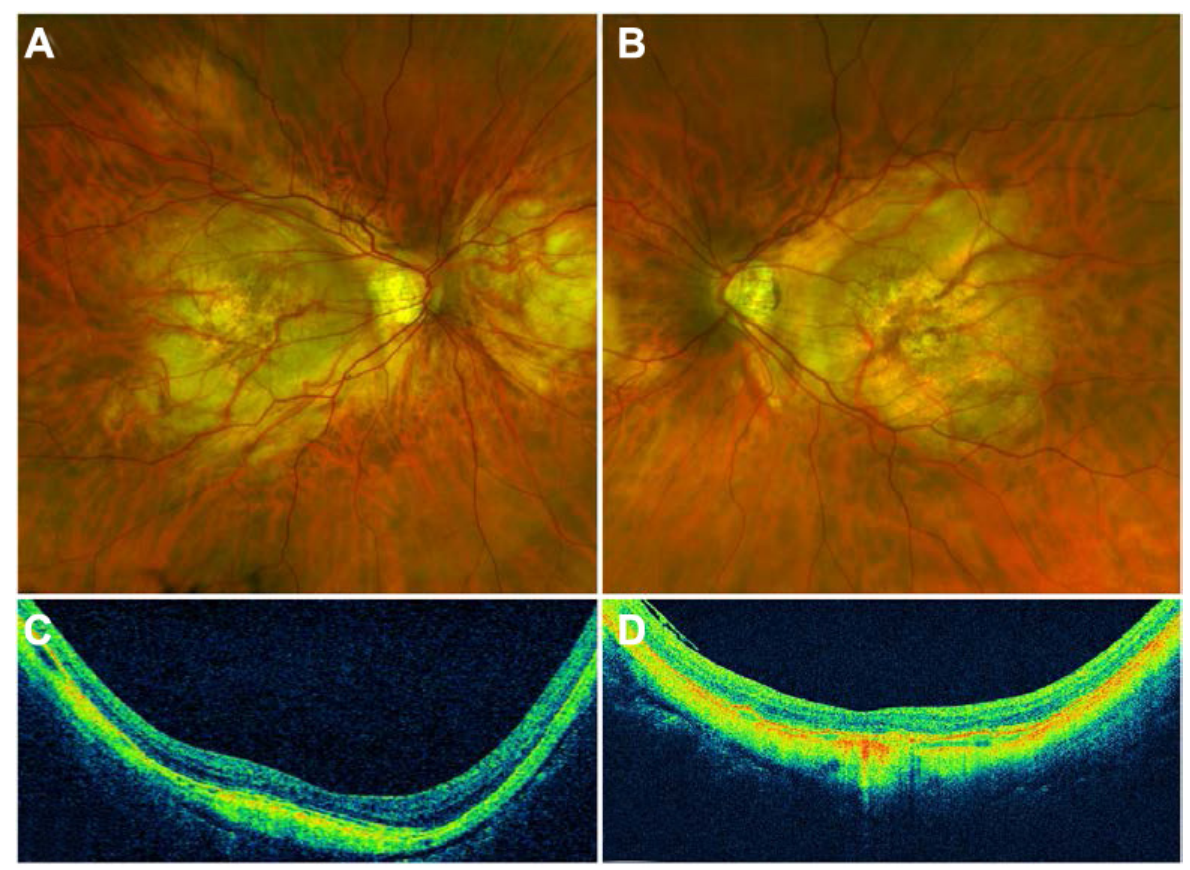

Figure I Postoperative Optos photography demonstrating tilted discs, peripapillary atrophy, macular pigmentary changes, and large posterior staphylomas in the posterior poles of the right (A) and left (B) eyes. Macula OCT images demonstrate posterior staphylomas in the right (C) and left (D) eyes.

Abbreviation: OCT, optical coherence tomography.

visit, her BCVA was RE 20/40 and LE 20/50, with respective refractions of $-5.75+1.25 \times 1.00$ and $-4.75+0.75 \times 085$. The patient showed subjective improvement in her daily activities and could read without glasses using the moderate residual myopia after surgery.

\section{Case report 2}

A 44-year-old woman developed progressively worsening cataracts in both eyes. Her BCVA was RE 20/60, and there was no light perception in the LE due to a longstanding retinal detachment. The patient's manifest refraction was $\mathrm{RE}-32.00+4.00 \times 165$. The RE showed a prominent nuclear sclerotic and cortical cataract. The posterior segment was notable for a tilted disc, peripapillary atrophy, posterior pole staphyloma, macular retinal pigmentary epithelial changes, peripheral laser scars, and lattice degeneration (Figure 2). The LE examination was significant for a longstanding open-funnel retinal detachment. The A-scan measurements demonstrated an axial length of $33 \mathrm{~mm}$. The patient underwent PPV/PPL with an initial improvement in BCVA to RE 20/25-2. At the 5-year postoperative visit, BCVA was 20/70 due to prominent pigmentary atrophy in the macula. The manifest refraction was $-4.50+2.00 \times 150$ in the RE.
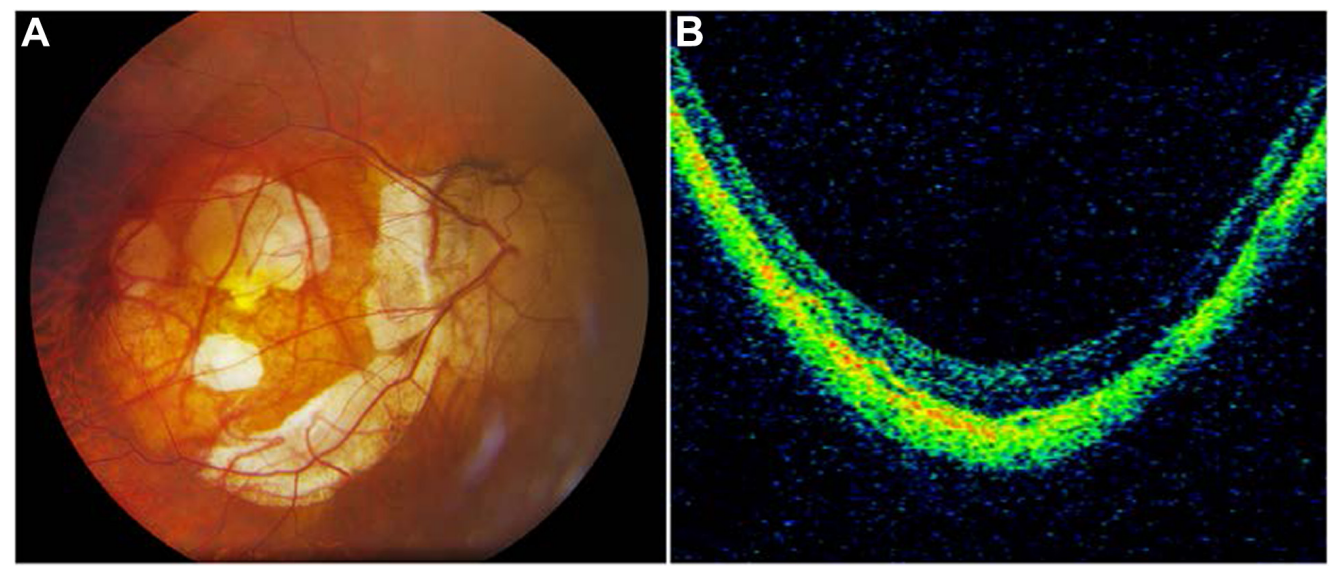

Figure 2 Fundus photo of the right eye (A) demonstrating a tilted disc, peripapillary atrophy, macular pigmentary changes, and large staphyloma, which is also demonstrated on macula OCT (B).

Abbreviation: OCT, optical coherence tomography. 


\section{Discussion}

Patients with severe pathologic myopia with high axial length can be managed by standard phacoemulsification techniques and IOL insertion. Special-order IOLs can be obtained, but A-scan measurements may be difficult and unreliable. Further, even in the presence of aphakia, the postoperative refractive errors range from moderate to high myopia.

An alternative surgical technique to cataract surgery in such patients with severe pathologic myopia is the use of a pars plana approach and avoidance of IOL insertion, because aphakia may achieve nearly emmetropic refraction while avoiding a larger incision for IOL insertion. Intraocular pressure has been reported to fluctuate throughout the surgical process in femtosecond laser-assisted cataract surgery, phacoemulsification, and any other intraocular surgery. ${ }^{6,7}$ Most surgeons place considerable emphasis on maintenance of intraocular pressure in eyes with pathologic myopia that are susceptible to rapid fluctuations in pressure due to a lack of scleral rigidity. The use of an anterior chamber maintainer may be a useful adjunct during standard clear corneal phacoemulsification in these eyes. ${ }^{8,9}$ This way, by decreasing scleral collapse during entry and exit of the phacoemulsification tip, there may be a better chance of avoiding capsular rupture during the anterior segment approach. Following standard phacoemulsification and preservation of the posterior capsule, subsequent YAG laser capsulotomy is associated with increased rates of retinal detachment in eyes with high axial length..$^{10}$ In these patients, removing the vitreous and capsule during vitrectomy avoids this risk and allows the retinal surgeon the option of treating any induced retinal tears or lattice degeneration. Although the described alternative technique of PPL followed by PPV is not a new approach, its use in the context of severe pathologic myopia with high axial length allows for maintenance of intraocular pressure and the ability to directly address retinal pathology during the surgical procedure as needed.

Prior to surgery, both patients described in this series utilized gas-permeable contact lenses because of the unfavorable cosmetic appearance of the thick lenses in spectacle correction. Following surgery, aphakia allowed the patients to be myopic, but spectacle correction for distance vision was much better. Although both patients had the option for contact lens wear, both elected to use spectacle correction and removal of glasses for reading. During the follow-up period, intraocular pressures remained within the normal age and no retinal complications have arisen.

\section{Institutional review}

This study was deemed exempt from full review according to the University of Miami Miller School of Medicine IRB as the study involved fewer than 3 patients. Written informed consent was obtained from both patients.

\section{Acknowledgments}

NIH Center Core Grant P30EY014801, an unrestricted grant, was provided to the University of Miami by National Eye Institute and Research to Prevent Blindness, New York, NY, USA. Department of Defense provided DOD-Grant\# W81XWH-13-1-0048, an unrestricted grant, to the University of Miami.

\section{Disclosure}

The authors report no conflicts of interest in this work.

\section{References}

1. Zuberbuhler B, Seyedian M, Tuft S. Phacoemulsification in eyes with extreme axial myopia. J Cataract Refract Surg. 2009;35(2):335-340.

2. Zaldivar R, Shultz MC, Davidorf JM, Holladay JT. Intraocular lens power calculations in patients with extreme myopia. J Cataract Refract Surg. 2000;26(5):668-674.

3. Ripandelli G, Scassa C, Parisi V, Gazzaniga D, D’Amico DJ, Stirpe M. Cataract surgery as a risk factor for retinal detachment in very highly myopic eyes. Ophthalmology. 2003;110(12):2355-2361.

4. Neuhann IM, Neuhann TF, Heimann H, Schmickler S, Gerl RH, Foerster MH. Retinal detachment after phacoemulsification in high myopia: analysis of 2356 cases. J Cataract Refract Surg. 2008;34(10): 1644-1657.

5. Seward H, Packard R, Allen D. Controversies in ophthalmology: Management of cataract surgery in a high myope. Br J Ophthalmol. 2001;85:1372-1378.

6. Baig NB, Cheng GP, Lam JK, et al. Intraocular pressure profiles during femtosecond laser-assisted cataract surgery. J Cataract Refract Surg. 2014;40(11):1784-1789.

7. Pardianto G. Recent awareness and consideration of intraocular pressure fluctuation during eye surgery. J Cataract Refract Surg. 2015; 41(3):695

8. Blumenthal M, Moisseiev J. Anterior chamber maintainer for extracapsular cataract extraction and intraocular lens implantation. J Cataract Refract Surg. 1987;13(2):204-206.

9. Blumenthal M, Assia EI, Chen V, Avni I. Using an anterior chamber maintainer to control intraocular pressure during phacoemulsification. J Cataract Refract Surg. 1994;20(1):93-96.

10. Ranta P, Tommila P, Kivelä T. Retinal breaks and detachment after neodymium: YAG laser posterior capsulotomy: five-year incidence in a prospective cohort. J Cataract Refract Surg. 2004;30(1):58-66. 


\section{Publish your work in this journal}

Clinical Ophthalmology is an international, peer-reviewed journal covering all subspecialties within ophthalmology. Key topics include: Optometry; Visual science; Pharmacology and drug therapy in eye diseases; Basic Sciences; Primary and Secondary eye care; Patient Safety and Quality of Care Improvements. This journal is indexed on

Submit your manuscript here: http://www.dovepress.com/clinical-ophthalmology-journal
PubMed Central and CAS, and is the official journal of The Society of Clinical Ophthalmology (SCO). The manuscript management system is completely online and includes a very quick and fair peer-review system, which is all easy to use. Visit http://www.dovepress.com/ testimonials.php to read real quotes from published authors. 